\title{
How I ran a virtual research retreat during a pandemic
}

\author{
Rob Salguero-Gómez shares how he ran a virtual lab retreat with his group
}

On April 5, two weeks into the UK lockdown, my lab group and I were due to fly to Ireland for our first virtual research retreat since I became a faculty member in ecology at the University of Oxford, UK. The goal of the retreat, due to be held in a manor house in Tipperary County, Ireland, was to enhance team dynamics and advance research projects.

Despite the lockdown, I wanted to go ahead with the retreat and organised a virtual version of it with the help of technology, some team organisation, and socially-distanced activities.

Here are some steps we took to make the retreat a success:

1. Pitch the idea to your group: Once it became clear that the in-situ retreat wasn't possible, I organised an hour-long video-conference with my group the week before to discuss options: cancel, postpone, or do something different. The democratic vote was a virtual format now, with the in-situ one postponed until safe.

2. Plan together: At that online meeting, I asked my team what format and rules they would prefer for the virtual retreat. We agreed to start each day at 9am by stating everybody's goals for the day, and continue our professional activities until 5pm, with two $30 \mathrm{~min}$ breaks for morning and afternoon coffee, and a $1 \mathrm{~h}$ break for lunch.

These breaks gave members the opportunity to chat informally via a video call. We also organised a series of 30-minute skills workshops after lunch, run by volunteers from the lab, on academic writing, research presentations, and grant proposal development. It soon became clear to me that the schedule needed to be flexible since one of my postdocs is a night owl, and two PhD students are currently based in Brazil and California.

3. Choose one thing only: To help lab members be more productive during the retreat, I asked them in advance to choose one project to focus on. Projects ranged from analyses, to writing manuscripts, essays or grants.

4. Protect your group from emails and other online temptations: A week before the retreat, I encouraged my students and postdocs to identify the 'urgent' emails that needed to be dealt with in advance. All else would have to wait until after the retreat. As a lab, we turned on our "out of office" automatic reply. We agreed to not check email during the writing slots of the retreat.

5. Build in relaxing activities: In the absence of the Irish manor house and its surroundings, we organised social activities from $5 \mathrm{pm}$ on, including virtual drinks and a pub quiz. We also found that having a time to go for a (socially-distanced) walk to the backyard, to disconnect from the monitor, was invaluable.

6. Provide feedback individually: I contacted each member individually to check in and provide feedback on their projects. This was very useful to them, in that it allowed 
them to not get stuck as I was focusing on my grant. Doing this, as it turned out, also allowed me to optimise the ramifications of my COVID-19: half-way through the week, I shared with my lab members my struggles in trying to write my grant proposal due to the loss of "creative ability" that COVID-19 had inflicted on me. After some careful consideration, we decided that I'd take a bit of a back-seat, and that my lab members would run the remaining activities for the rest of the week. This allowed me to focus on providing critical feedback - an ability that coronavirus had not taken away from me.

7. Organise a final wrap up: We used the last hour of the writing retreat to discuss each members' progress, trials, and tribulations, including my own. Sharing struggles regarding lack of motivation to write, but also tips to do so efficiently, was greatly appreciated across all team members. Next, we each explained future steps, as well as a rough timeline.

8. Keep track of progress after the retreat: I meet individually with my lab members weekly. Now we discuss the progress of retreat-related projects. In the past, I have attended writing retreats where members were assigned a partner to check progress every two weeks. This strategy may provide a sense of support and accountability. I also organised a poll to ask for feedback on the event.

9. Keep the motivation going: I did not cancel the in-situ retreat in Ireland, but postponed it until it's safe to carry it out. Most weeks, at our (now also) virtual lab meeting, I remind my lab of this promise. This prospect gives them a sense of light at the end of the tunnel.

10.

Delegate: Once I had taken care of the basic structure of the retreat and run the first, I asked volunteers to help keep the time and moderate events in the subsequent events. This is always a good idea, as it provides team members with the ability to exercise these key skills. However, it was also rather convenient for me: a couple of weeks before the retreat, my wife and I started displaying the symptoms of coronavirus. We were not deemed ill enough by our GP to go to hospital. Instead, we managed our symptoms from home with some medicines and rest.

Halfway through the retreat I shared struggles I had faced trying to write a grant proposal due to the loss of "creative ability" that COVID-19 had inflicted on me. After some careful consideration, we decided that I'd take a bit of a back-seat, and that my lab members would run the remaining activities for the rest of the week. This allowed me to focus on providing critical feedback - an ability that coronavirus had not taken away from me.

Carrying out the retreat virtually helped me navigate a novel challenge, while hopefully providing my team with the necessary support they need in the midst of the pandemic. 